\title{
El fracaso del diálogo migratorio transatlántico en Vientos de agua.
}

\section{The Failure of the Transatlantic Migratory Dialogue in Vientos de agua.}

\section{Resumen}

Este artículo analiza las connotaciones afectivas del diálogo transatlántico que propone la serie hispano-argentina Vientos de agua en su proyecto de instaurar una comunidad de significado común para todos los sujetos víctimas de estructuras de dominación, ya sean políticas o económicas. A través de las historias paralelas de Argentina y España, se establece una conexión entre el poder disruptivo del fascismo español a principios del siglo XX con el del capitalismo en Argentina a principios del siglo XXI. Vientos de agua propone la deconstrucción de una serie de estructuras binarias herederas del discurso colonial a partir de las categorías universales de víctima e inmigrante. Consideramos este proyecto fallido dado el tratamiento de ciertos personajes que en última instancia quedan excluidos del circuito afectivo. Concluimos que estas estrategias se resuelven en la preponderancia del espacio peninsular, así como en la exclusión del elemento indígena y africano de la supuesta nueva comunidad de significado, resultando en el fracaso del diálogo migratorio transatlántico.

Palabras claves

Dialogo transatlántico, afecto, migración, fascismo, crisis, víctima universal

\begin{abstract}
This article analyzes the affective connotations of the transatlantic dialog proposed by Vientos de agua, a Spanish-Argentinean TV show. It is it's project to establish a community for all the victims of structures of domination, may them be political or economic. Across the parallel histories of Argentina and Spain, a connection is established between the disruptive power of the Spanish fascism at the beginning of the 20th century, and that of the capitalism in Argentina at the beginning of the 21th century. Vientos de agua proposes the deconstruction of the binary structure inherited from the colonial momentum by creating the universal categories of victim and immigrant. We consider this project failed in view of
\end{abstract}


the treatment of certain figures who in last instance remain excluded from the affective circuit. We conclude that these strategies end in the prevalence of the peninsular space, as well as in the exclusion of the indigenous and African element from the supposed new community, resulting in the failure of the migratory transatlantic dialogue.

Keywords Transatlantic dialogue, affect, migration, fascism, economic crisis, universal victim.

La serie Vientos de agua es una coproducción hispano-argentina de 2005 dirigida por Juan José Campanella. En España, se emitió por la cadena Telecinco entre los meses de enero y febrero de 2016. Tras la emisión de los primeros cuatro capítulos (de un total de trece) fue cancelada por su baja aceptación. En Argentina, fue emitida íntegramente por el Canal 13 estrenándose el 21 de mayo de 2016. Esta serie pretende establecer un diálogo entre España y Argentina que se articula gracias a sendas narrativas de inmigración ambientadas una en la década de los treinta, otra a principios del siglo XXI. Existe en estos países una larga tradición cinematográfica que atiende a las problemáticas migratorias. Películas como La Patagonia Rebelde, en Argentina, o El emigrante en España, lo demuestran. La singularidad del caso analizado (Vientos de agua) radica en que es una coproducción internacional (Telecinco, Pol-ka y 100 Bares) que ha sido emitida en ambos países y cuya temática atiende a procesos migratorios distantes en el tiempo y en el espacio. Ello permite un análisis comparativo desde los estudios de lo transatlántico que no sería posible en otro tipo de producciones.

Durante trece capítulos se narran las historias paralelas de un inmigrante español en Argentina y la de su hijo en España. En el primer caso, José abandona su pueblo natal (situado en Asturias, España) en 1934. Su salida del país se da en el contexto de las revueltas mineras que fueron una de las principales manifestaciones de la conocida como Revolución de 1934, brutalmente reprimida por las fuerzas militares que más tarde se alzarían con el poder en el país y que acabarían instaurando una dictadura militar que duró hasta 1975. En el segundo caso, su hijo Ernesto, emigra a España desde Buenos Aires (Argentina) en un 
CATEDRAL TOMADA: Revista literaria latinoamericana / Journal of Latin American Literary Criticism Ignacio Dionisio Arellano-Torres

contexto de crisis económica tras la imposición del corralito argentino en 2001 y como consecuencia del colapso del sistema financiero.

El objetivo de este trabajo es analizar las estrategias narrativas que sirven para el establecimiento de un diálogo en el que el elemento afectivo trabaja en la disociación del significado respecto del significante histórico. Esto se da tanto en su vertiente espacial como en el plano temporal, eliminando las connotaciones históricas e ideológicas de los traumas colectivos que sirven como punto de partida de las historias paralelas de José y de su hijo Ernesto: la Revolución de 1934 y la crisis económica en Argentina en el 2001. Vientos de agua intenta configurar una nueva comunidad de significado sostenida por la universalización de las categorías inmigrante y víctima. Esta categoría permite la integración tanto de José como de Ernesto en una nueva forma social que excede lo nacional: la sociedad inmigrante.

En esta nueva sociedad inmigrante, los valores hegemónicos del imaginario del espacio receptor (Argentina en el caso de José y España en el caso de Ernesto) quedan anulados. Esto permite la transformación y desbordamiento del sujeto diaspórico que está sometido a ese imaginario hegemónico, "El sujeto diaspórico, a diferencia del inmigrante, no se asimila a la sociedad anfitriona, resiste a la interpelación del imaginario hegemónico" (Trigo 276). Es decir, la nueva comunidad, forjada en el diálogo afectivo transhistórico y transatlántico, permite una forma social que elimina las connotaciones de lo diaspórico y abraza una nueva identidad: lo migrante. En el discurso de Vientos de agua, se aboga por la construcción de una nueva comunidad imaginada. El concepto acuñado por Benedict Anderson en Imagined communities sirve como punto de partida para el análisis de la serie, aunque, en este caso, es la comunidad migrante la que proyecta esta visión de lo colectivo. Para Anderson, los medios tecnológicos (especialmente la imprenta) tienen un papel fundamental en la formación de estas comunidades imaginadas. En Vientos de agua, el producto cinematográfico cumple una función análoga a la imprenta, ya que se caracteriza por facilitar el acceso al contenido simbólico que permite a los sujetos imaginar la comunidad. 
El soporte audiovisual, así como la naturaleza transnacional de la coproducción, facilita este proyecto. Esto es, la serie es un producto de aspiraciones fundacionales de una nueva comunidad de significado híbrida que traspasa tanto las fronteras geográficas como las temporales. Formaría parte de una nueva narrativa de lo cultural con objetos y sujetos de enunciación que subvierten el orden tradicional. Como expone Homi Bhabha, en The Location of Culture, "there is an overwhelming evidence of a more transnational and translational sense of the hybridity of imagined communities" (7). Es decir, el proyecto de la serie queda identificado como el resultado de una hibridez esencial que sirve para crear un espacio liminal desde donde una nueva enunciación es posible, desbordando el encorsetamiento simbólico de lo nacional y lo colonial.

Este proyecto, caracterizado por el movimiento, está relacionado con la configuración de lo identitario a través de lo afectivo. La trasmisión de los afectos va más allá de la mera trasferencia de los saberes epistemológicos. A nivel intradiegético, los afectos, "play a critical role in both shaping the migration experience and reproducing transnational connections" (Vise and Velayutham 127). En este sentido, Ernesto cuenta con las herramientas (no epistemológicas, sino afectivas) para moverse en su nuevo hogar. A nivel extradiegético, la posición del encuadre narrativo sitúa al espectador en el circuito fluyente de las experiencias migratorias, haciéndole partícipe de lo traumático, pero también de las bondades asociadas a las migraciones de José y Ernesto.

Como señala Bhabha, en Nation and Narration, las estrategias narrativas son el fundamento básico de la articulación de lo nacional a la vez que permiten una ambivalencia de significado. La narrativa de Vientos de agua aboga por una construcción que excede esta categoría de lo nacional. No es un discurso de nation and narration, es un discurso de migration and narration. Este discurso es enunciado desde el espacio de lo ambivalente, ya que en lo liminal existe la posibilidad de enunciar una narrativa que subvierta las categorías de lo nacional y lo colonial. Vientos de Agua se presenta como el producto ficcional que reproduce el lugar de enunciación nacido desde el "time of gathering. Gatherings of exiles 
CATEDRAL TOMADA: Revista literaria latinoamericana / Journal of Latin American Literary Criticism Ignacio Dionisio Arellano-Torres

and emigrés and refugees, gatherings on the edge of "foreign" cultures" (Bhabha 291).

La intención de establecer una afectividad compartida, enunciada desde un espacio y un tiempo configurados y configuradores de esa comunidad en los márgenes de las culturas nacionales, es marcada desde el principio del primer capítulo a través del uso de la música y la imagen. La serie comienza narrando la historia de José y el resto de los mineros asturianos, entre los cuales se encuentra su hermano Andrés. El elemento acústico de reminiscencias argentinas es disociado de su significante nacional al ser superpuesto con el espacio asturiano. En este proyecto de deconstrucción, más allá de las técnicas formales, Vientos de agua propone la reconstrucción de una serie de significantes (víctima e inmigrante) que sean capaces de articular los binarios diacrónicos y diatópicos de las relaciones transatlánticas y coloniales en una nueva realidad. La estrategia consiste, como ya he apuntado, en vaciar las connotaciones contextuales de los traumas colectivos. La Revolución de 1934 es introducida a través de su reducción a lo particular. Es descrita como la respuesta a un accidente que los obreros sufren en la mina y donde muere Andrés (hermano de José) quien pretendía emigrar a Argentina. La revolución es reducida a la respuesta pasional de la víctima a las dinámicas de poder patronal y político que acaban desembocando en la llegada del fascismo a España. José pone una bomba en la mina para evitar que más obreros mueran por culpa del sistema productivo. Este sistema se encuentra amparado por las fuerzas institucionales: Iglesia y Guardia Civil. La relación entre sistema económico, generador de cuerpos-víctima, y las estructuras defensoras de los fenómenos de opresión (económica, ideológicapolítica, espiritual, emocional-afectiva) queda ya definida. Esto es, para lograr la identificación afectiva entre víctimas del protofascismo en España y las víctimas del sistema financiero en el caso argentino, se ha de subrayar el componente económico del primer proceso.

En la formación de la categoría universal víctima, que sirve para establecer las conexiones afectivas a las que aspira la serie, la figura del judío es 
un elemento clave. Juliusz, un húngaro judío al que José conoce en el barco que les lleva a Argentina, discute con un alemán nazi. Este pretende que los pasajeros de las clases económicas desfavorecidas pasen la noche en cubierta. Lo hace para poder ocupar temporalmente su espacio habitacional, ya que un incendio (provocado por un resistente antifascista) ha inutilizado los camarotes de primera clase. La respuesta de José y el conjunto de inmigrantes (italianos, rusos y españoles), que ya han formado una propia comunidad, es el de identificarse todos ellos como judíos. En este sentido, toda la comunidad de inmigrantes establece una solidaridad afectiva con la víctima simbólica por excelencia: el judío. La intención de transferir la connotación simbólica del judío como víctima queda reforzada por la narrativa paralela que protagoniza Ernesto. Ernesto viaja en un taxi y se ve envuelto en Buenos Aires por las protestas que surgen contra el sistema financiero. El conductor del taxi equipara a los manifestantes (víctimas del capital) con el elemento emigrante boliviano. La respuesta de Ernesto es identificarse él mismo como boliviano, replicando el gesto de los emigrantes del barco. Es decir, Ernesto se identifica ya desde Argentina con la comunidad imaginada de la diáspora a través de su identificación como boliviano, concepto asociado a su vez por el taxista con las víctimas del sistema financiero. Así queda reforzada la trasferencia que la serie hace entre fascismo y capital como sistemas análogos de producción de víctimas. En esta doble identificación, de José y de Ernesto, con la víctima simbólica en Europa y con el inmigrante simbólico en Argentina, la otredad queda asumida en el nuevo proyecto colectivo. Para entender esto hay que subrayar que, en el barco, son los nazis quienes viajan en primera clase y disfrutan de privilegios. El plano económico y las dinámicas de producción de víctimas del fascismo quedan completamente equiparadas en el espacio del barco. El significante inmigrante asume las connotaciones del exilio ya sea por cuestiones de violencia política, racial, étnica o económica, "Though it can be either voluntary or involuntary, internal or external, exile generally implies a fact of trauma, an imminent danger, usually political, that makes the home no longer safely habitable" (Peters 19). 
Ernesto, arquitecto, tiene deudas y problemas económicos que se ven agravados por el corralito de 2001. La restricción del acceso a sus ahorros convierte a Ernesto en víctima y permite convertir su migración en una experiencia traumática de carácter individual al no poder ser acompañado por su familia. Esta es una estrategia que funciona en paralelo con la historia de José. Los traumas colectivos son expresados a través de lo individual para reforzar el diálogo transhistórico y transatlántico y no centrarse en los traumas colectivos nacionales que vendrían a reforzar el discurso de lo identitario en el ámbito de lo nacional. La historia traumática se presenta como el elemento que permite la imaginación de la nueva comunidad afectiva. Este recorrido por la historia traumática ayuda a la serie a establecer un juego diacrónico entre el pasado y el presente a la vez que establece un continuum transatlántico. Esta línea de continuidad se logra a través de diversas estrategias narrativas como el paso encadenado entre dos planos. Vemos, en un primer plano, a los mineros asturianos frente al océano Atlántico. Esa misma imagen que ven los asturianos aparece repetida, en la escena siguiente, en un folleto turístico que tiene José en su casa cuando ya es mayor. Este juego de planos enlazados nos introduce en el espacio argentino, en otra temporalidad, a través de los elementos espaciales. El océano juega un papel simbólico central; el personaje de Andrés lo define como una "ventana". Lo particular de este umbral no es su transitabilidad, sino el establecimiento de una potencial comunidad de observadores partícipes de un mismo marco de referencia, de un imaginario colectivo compartido. En términos de creación de colectividades, el barco que transita esta frontera también cumple un papel esencial. Funciona como un espacio heterotópico. Foucault, en Of Other Spaces, considera el barco como uno de los espacios heterotópicos por excelencia. En el caso que nos ocupa, el Aquitanie, se comporta como un espacio permeable a la jerarquización de clases económicas del mundo exterior, pero también a la presencia de las dinámicas de represión racial por parte del nazismo. Es decir, es el canal a través del cual se permite la heterocronía del diálogo migratorio, entre los dos ámbitos transatlánticos, en la temporalidad yuxtapuesta de la serie (donde 
el fascismo y el capitalismo quedan asociados). El barco permite las redes transatlánticas de diálogo afectivo migratorio, permite acumular temporalidades diversas. Al mismo tiempo, configura, a través de la posibilidad de atravesar la ventana simbólica de lo Atlántico, ese imaginario compartido. Este compartir afectivo, en teoría, imposibilitaría la mirada desde un enfoque caracterizado por la imperial gaze de la que habla Kaplan. Debido al desplazamiento del locus de observación de la metrópoli al espacio fronterizo, la mirada desde el espacio liminal permite la subversión frente a las estructuras generadoras de la imperial gaze, "The concept of being in-between allows for the multiple identities, coexisting and held in suspension" (Kaplan 18). Esto es, el espacio móvil dificultaría la mirada imperial del sujeto masculino colonial.

Como muestra el ejemplo del océano y del barco, los componentes espaciales en la serie tienen una gran fuerza simbólica. Para problematizar la conexión entre un lugar y el lugar que no-es el anterior, con el fin de ayudar al proyecto de la serie en su deconstrucción de los binarios, hacen falta espacios de tránsito: los no-places, "palimpsests on which the scrambled game of identity and relations are ceaselessly rewritten" (Augé 79). Tanto en la historia de José como en la de Ernesto (que como insiste la serie son una misma, Ernesto le dice a su padre que sus recuerdos son también suyos), estos espacios son fundamentales en la problemática identitaria. Se hace uso de estos espacios de tránsito, escenarios del flujo de la llegada y partida de la migración para reflejar una "interpretación audiovisual postmoderna del concepto de la identidad. Esto se debe al hecho de que, tanto en la narración como en la visualización, la miniserie subraya la fragmentación y fluidez de la identidad individual" (Berger 44). En la aduana, uno de estos no-places de tránsito, José lleva la documentación de su hermano. Cambia su nombre y asume el significante de Andrés. Al final de la serie, padre e hijo están sentados en el cementerio frente a la tumba de José Olalla. En esta escena, la migración simbolizada por el desarraigo y el entierro simbólico de José (recordemos que es Andrés quien está muerto) supone un trauma identitario en el minero asturiano (y en su hijo Ernesto). El viaje de regreso a España es el 
elemento que permite superar ese conflicto. Es decir, si bien existe fragmentación y fluidez, no es sino hasta el regreso de esas aguas al cauce asturiano (hasta la recomposición de la fragmentación con el espacio primigenio) cuando se supera el trauma.

A pesar de compartir una misma historia, la emigración de Ernesto es diferente a la de su padre José. El viaje en avión queda omitido a través de una elipsis cinematográfica y vemos a Ernesto directamente en España. La posibilidad de crear una comunidad de viaje que tendrá continuación en el país de acogida queda aquí omitida. En el caso de Ernesto, es su condición de extracomunitario ${ }^{1}$ lo que define su identidad en el aeropuerto de Madrid, el equivalente simbólico a la aduana que transitara su padre en 1934. El personaje se acaba naturalizando español tras dos años, con lo cual se resuelve el problema identitario a través de la doble nacionalidad. Un regreso a sus orígenes. Es decir, tanto José como Ernesto resuelven sus conflictos en el ámbito peninsular. El nacimiento del nieto (de José) e hijo (de Ernesto) supone un elemento de arraigo con el espacio asturiano originario de los Olalla. El apellido paterno y el viaje de regreso a la patria excluye de este circuito al elemento femenino. A través de una continuidad en el ámbito de la filiación de las figuras masculinas, queda completamente omitido el espacio simbólicamente femenino de las Américas. Esto queda subrayado a partir de varios elementos: el divorcio de José con Cecilia, que se vuelve a Argentina; la negativa de su hija a viajar a España y, por último, la muerte de las figuras femeninas americanas con las que José Olalla mantuviera relaciones amorosas. Todas han muerto, excepto la española Henar, antiguo amor de José a quien siempre prometió que volvería a buscar. En el discurso aparentemente deconstructor de lo binario subyace una retórica de género que representa a América como el espacio de deseo de apropiación colonial. Este espacio ha de ser abandonado para reinstaurar el orden anterior a los traumas colectivos: José, estereotipo del conquistador, vuelve al final de la serie a casa de su primer amor;

${ }^{1}$ El término extracomunitario hace referencia a los naturales de países que no pertenecen a la Unión Europea y que por lo tanto no se benefician de las políticas de libre tránsito. 
Ernesto, ya naturalizado, es padre de un niño nacido en España (proyectándose su permanencia en el país). Por otra parte, Mara (nueva pareja de Ernesto), pasa de ser una figura en la que convergían la sexualización de la mujer caribeña (ella es colombiana) con un discurso que venía a derrumbar este mismo estereotipo (es matemática y lee a Unamuno), a acabar resolviendo su identidad en cuanto madre. En cuanto a la doble nacionalidad y el conflicto identitario intergeneracional, es importante señalar que los tres actores protagonistas masculinos poseen la doble nacionalidad hispano-argentina. Ernesto Alterio y Héctor Alterio son hijo y padre respectivamente en la vida real. En la ficción, ambos representan al mismo personaje en un gesto que representa la voluntad de establecer ese diálogo afectivo. Esta intención responde a un proyecto ideológico de subversión frente a las estructuras de poder discursivas. Las historias personales de Héctor Alterio, quien tuvo que exiliarse en España por las amenazas de la Triple A argentina, y de su hijo Ernesto (nombrado así en homenaje a Ernesto Guevara) subrayan este proyecto ideológico. En el elemento ideológico de la serie, durante la convalecencia de Andrés, Henar intenta rezar un rosario. La madre reacciona negativamente, pero termina por tolerarlo. Las connotaciones políticas e ideológicas del catolicismo, en el contexto de los preliminares de la Guerra Civil, permiten considerar al rosario como una discursividad más allá de la mera espiritualidad. En este gesto de tolerar el componente religioso se introduce uno de elementos que complejizan el análisis de la serie. El establecimiento universal de la categoría víctima está estableciendo así mismo la categoría productor-devíctimas. El recurso del que hace uso la serie para deconstruir este nuevo binario generado es el de la colaboración de las autoridades con las dinámicas de resistencia. La participación institucional de las estructuras que soportan el fascismo (o el capital) actúan en favor del sujeto diaspórico.

Retomando la escena de la explosión provocada por José mencionada al comienzo de este trabajo, es necesario comentar que una pareja de Guardias Civiles acude a la casa para buscar al culpable. Uno de los Guardias Civiles intercede por la familia al afirmar que solo existe un hijo en ella, Andrés (muerto 
en el accidente), al que queda desde entonces asociado el significante José. Es la complicidad de los sostenes del inminente régimen fascista lo que permite la disociación de significante y significado. En la llegada a Argentina de José, es el funcionario de la autoridad aduanera el que permite la entrada en el país del asturiano. Lo hace independientemente de la evidente falta de concordancia entre significado (José) y significante (Andrés), como demuestra la documentación que porta. Felisa, hermana de José, que durante los años de la Guerra Civil española había vivido con los maquis y había participado en la resistencia, también llega a Argentina. Tras una sorprendente transformación de revolucionaria a beata, acaba trabajando en un hospital rural gracias a la colaboración de uno de los soldados del nuevo régimen impuesto en Argentina tras la caída del peronismo de Evita. También es necesaria la ayuda del cura del lugar. Esto es presentado como una continuidad de la lucha de resistencia de Felisa, como una vuelta a los orígenes en la lucha contra la desigualdad, pero esconde un trasfondo de sumisión a las estructuras de poder religiosas y heteronormativas. Es en realidad un martirio simbólico que permite que la segunda esposa de José vuelva a Buenos Aires a formar una familia. La solución que propone la ficción es (desde el punto de vista de la articulación de un discurso de resistencia frente al fascismo y el capital) cuanto menos problemática. Se establece un diálogo afectivo en las comunidades de memoria devenidas de los fenómenos colectivos traumáticos. Como símbolo de esta nueva variante del diálogo afectivo, uno de los hijos de José (Joaquín), llevará el nombre del funcionario de aduanas que permitiera su entrada en el país. Las dinámicas de migración y trauma son de nuevo reducidas al ámbito de lo particular para reforzar la retórica afectiva y entran en conflicto con el componente universal al que aspira la serie.

Otro de los elementos ideológicos y políticos a los que atiende la serie, y que permiten ver los recursos del estereotipo en la articulación y definición de las colectividades a las que se hace sujetos plausibles de pertenencia de una misma comunidad de significado a través del diálogo afectivo, es el anarquismo. José se integra en el grupúsculo anarquista en Argentina. La figura del anarquista es 
identificada con el "soñador", adjetivo al que se recurre constantemente para definir a los tres personajes entre los cuales se da una clara trasferencia: Andrés (el hermano muerto), Vidal, un anarquista español que viene a ocupar el lugar del fallecido ("me recuerda mucho a alguien"), y Ernesto. Esto es, la ingenuidad y lo pasional son identificadas con el movimiento anarquista formando un estereotipo que requiere necesariamente de una enunciación deudora de lo binario para justificar su existencia (deseo y sueño-realidad, y hecho histórico), todo ello a pesar de que la serie intente complejizar el fenómeno anarquista. A Vidal se le reprocha considerar al movimiento como, "loquitos que visten de negro y tiran bombas". A nivel de narrativa, la serie hace exactamente lo mismo desde el comienzo, donde la Revolución de 1934 es descrita como la respuesta pasional a la muerte del hermano.

Los protagonistas, emigrante español, emigrante argentino, se caracterizan por su bondad e ingenuidad intrínseca, son el "tonto". Existe una infantilización de estos personajes que reproduce a nivel concreto la consideración que se hace sobre el movimiento anarquista. Existe un tono de condescendencia con el anarquismo generalizado a través de toda la serie. Intenta disociar el anarquismo de la bomba, de la corriente de la propaganda por el acto (el anarquismo expropiador en Argentina), con el fin de descontaminarlo del elemento violento y facilitar así la identificación afectiva a través de la categoría de víctima. Esta apelación no funcionaría si se apelase a la categoría universal de productor de víctimas, que como hemos visto se intenta negar a través de la posibilidad redentora en la colaboración de los partícipes de la autoridad en las dinámicas de inmigración y diáspora.

En relación con lo ideológico y las respuestas políticas a las desigualdades del sistema productivo, las profesiones también sirven para crear continuidades. En el viaje en barco, durante una tormenta, el minero baja a la caldera para sentirse cerca del carbón, de lo familiar. Hay una relación directa entre lo material y espacial, y lo afectivo y familiar. La casa armada por las manos del matrimonio Ernesto y Cecilia recibe la afectividad transferida del pasado. Su venta supondría 
la ruptura total de esta relación. A través del divorcio se posibilita la subsistencia de esta. Pero es principalmente a través de una escena donde se percibe esta conexión. José, Ernesto y Tomás, que son respectivamente abuelo-padre, hijopadre, hijo; entran en contacto a través de la restauración de un mueble. El minero que mudó a carpintero en el espacio argentino, desde este mismo espacio, guía el trabajo de su nieto, que está en España, a través del teléfono. Ernesto actúa como mediador de un diálogo que une tanto geografías como cronologías diferentes a través de la trasmisión de saberes.

El fracaso de la serie viene determinado por la creación de un imaginario hegemónico que no permite la entrada de ciertos sujetos en esta nueva comunidad de significado. Algunos personajes como Mario, inmigrante boliviano en Argentina, imposibilitan la creación de una nueva identidad compartida. La exclusión de ciertos personajes de las dinámicas de deconstrucción del binario lastra la aspiración de la serie de establecer las categorías universales de víctima e inmigrante, algo fundamental para justificar el diálogo afectivo. La retórica de simplificación, y estereotipo, perpetúa la división de las estructuras de poder discursivas que aparentemente la serie viene a negar. En este proceso de deconstrucción de lo binario a través de la identificación de los personajes diaspóricos con las categorías universales de víctima e inmigrante, el tratamiento de la figura de Mario no corresponde a esta narrativa. Mario es un trabajador boliviano que ha colaborado con Ernesto y a quien se le adeuda cierta cantidad de dinero. Si bien hemos visto que Ernesto se identifica como boliviano, el trato que tiene con Mario tiene una fuerte connotación poscolonial de desigualdad económica, de clase social, de privilegio racial y de origen nacional. A pesar de supuestamente pertenecer ambos a una misma comunidad imaginada, Ernesto pone de su bolsillo el dinero que la empresa constructora le adeuda al boliviano, quien necesita el dinero para ayudar a su hijo con los gastos médicos de una operación. En esta narrativa la presencia de los hijos es fundamental desde el punto de vista simbólico, ya que permite la articulación de Ernesto como figura paterna capaz de proveer la solución para la familia de bolivianos. Este elemento 
simbólico queda reforzado más tarde cuando va a visitar la casa del trabajador para pagarle el resto de la deuda y su interlocutor es uno de los hijos pequeños de Mario. Es decir, la presencia de la figura del niño queda intrínsecamente relacionada con las dificultades que tiene el indígena boliviano en la sociedad bonaerense mientras que la figura de Ernesto queda directamente descrita como el posibilitador de la subsanación de dichas dificultades. La figura del niño, cuyo estado de maduración intelectual, física y afectiva, lo hacen más proclive a ser víctima, sustituye a la figura del adulto en las relaciones de Ernesto con el componente indígena en la serie.

El binario queda fuertemente marcado en estas secuencias, ya que reproducen el estereotipo colonial del indígena indefenso que permite la identificación del sujeto colonizador paternal más allá de la proclamación de independencia y las narrativas fundacionales. El indígena es visto como el fetiche que representa la posibilidad del deseo colonial donde el "otro" simbólico por excelencia, en este contexto, necesita de la presencia del sujeto colonizador para poder ser definido en relación a este. Lo colonial subsiste a través de la perpetuación del binario que la serie viene a deconstruir, ya que permite la proyección de la fantasía colonial como la define Bhabha en The location of culture, en su lectura de Fanon, "It is precisely this function of the stereotype as phobia and fetish that, according to Fanon, threatens the closure of the racial/epidermal schema for the colonial subject and opens the royal road to colonial fantasy" (104).

Otro de los personajes que quedan excluidos de la comunidad de inmigrantes universales, necesaria para sostener la existencia del diálogo afectivo en la narrativa de la serie, es el personaje de la prostituta africana. En el capítulo siete, ella huye de los abusos que sufre en el burdel e implica a Ernesto en una trama de resistencia. Ernesto pretende ayudarla a escapar de las redes de prostitución en las que se ve envuelta, pero el proyecto queda truncado dado que la víctima vuelve al prostíbulo y queda exenta de la posibilidad de compartir la misma comunidad de significado que la víctima universal simbólica del judío 
había ayudado a construir. El elemento racial en la serie es hasta cierto punto ambiguo. Mara, la colombiana con la que acaba teniendo un hijo Ernesto, rechaza una primera identificación que este hace de ella asociándola a la negritud en una escena que permite ver la raza como constructo social. La negritud, representada por el "otro" africano, así como la otredad indígena, quedan excluidas de una u otra manera de la comunidad de significado deseada, desestabilizando la base teórica en la que se funda Vientos de agua para fundamentar su proyecto afectivo. En relación con esta problemática poscolonial se encuentra la propuesta del viaje de retorno. El conflicto del que parte toda la narrativa tiene lugar en el ámbito peninsular y en este se resuelve. No solo Ernesto viaja a España, sino que también José vuelve a su pueblo en Asturias. América queda entonces como el espacio liminal de tránsito cuyas dinámicas son generadoras del deseo de retorno siendo entonces el establecimiento de las categorías universales de víctima e inmigrante poco efectivas, ya que la deconstrucción del binario es simplemente aparente. El espacio colonial queda representado en una situación de desventaja frente al espacio colonizador que permite la reestructuración familiar y la superación de las experiencias traumáticas que detonaron ambas historias de inmigración. Es el puerto de origen de las dinámicas discursivas implementadoras de un sistema de relaciones de dominación lo que en la serie viene a resolver la trama; el espacio Atlántico resulta un obstáculo insalvable en la configuración de una pretendida nueva comunidad de significado.

El proyecto de la serie fracasa, entre otras cosas, por causa de su dispar recepción en el ámbito argentino y en el ámbito peninsular. Hay una disimetría de la recepción que lastra el entendimiento en el diálogo transatlántico. Mientras que en Argentina fue un éxito comercial, en España fue retirada por la cadena Telecinco tras cuatro capítulos por su escasa cuota de pantalla. Tajes, en Hybridity in Spanish Culture, analiza el fracaso de la serie y defiende que es su hibridez lo que explica la imposibilidad de los sujetos de imaginar una comunidad en torno a esta producción transatlántica, "la hibridez creada por los constantes paralelismos entre la emigración española y otras migraciones hace que los televidentes 
españoles elijan entre reflexionar, revisar y reformular su actitud hacia la inmigración o cambiar de canal" (122). Es decir, en la misma articulación del producto híbrido se encuentra la génesis del rechazo afectivo que imposibilita el efecto al cual aspira este producto narrativo en el nuevo imaginario colectivo. El proyecto transatlántico existe principalmente en cuanto deseado, es una suerte de proyección sin efecto, es un deseo no actualizado.

En conclusión, el proyecto de Vientos de agua de establecer una comunidad inmigrante, donde los binarios herederos de las relaciones coloniales queden deconstruidos, fracasa por el tratamiento que hace de ciertos sujetos que quedan excluidos del proceso. Establece la categoría universal de víctima a través de la identificación paralela de José con los judíos, y de Ernesto con los inmigrantes bolivianos. Para ello equipara los traumas personales devenidos del fascismo en España y de la crisis económica en Argentina, descontextualizando las particularidades históricas de ambos fenómenos. El tratamiento que se hace del inmigrante boliviano, a través de la interlocución de Ernesto con los hijos de este, marca simbólicamente la pervivencia de un discurso racial de raigambre colonial que necesita de la permanencia del binario Atlántico.

\section{Bibliografía}

Auge, Marc. Non-Places. Introduction to an Anthropology of Supermodernity. Verso, 1995.

Berger, Verena. "Identidades multifocales en Vientos de agua (2005): La emigración en el Pasado y en el Presente." Estudios Interdisciplinarios de América Latina y El Caribe, vol. 24, no. 1, 2013, pp. 33-48.

Bhabha, Homi K. Nation And Narration. Routledge, 1990. . The location of Culture. Routledge, 1994.

Campanella, Juan José, creator. Vientos De Agua. Telecinco, Pol-ka and 100 Bares. 2005.

El emigrante. Directed by Sebastián Almeida, Vértice P.C, 1958.

Foucault, Michel. "Of Other Spaces." Diacritics, vol. 16, no. 1, 1986. pp. 22-27. 
Kaplan E. Ann. Looking for the Other: Feminism, Film and the Imperial Gaze. Routledge, 1997.

La Patagonia Rebelde. Directed by Héctor Olivera, Aries Cinematográfica Argentina, 1974.

Peters, John Durham. "Exile, Nomadism and Diaspora. The Stakes of Mobility in the Western Canon." Home, Exile, Homeland: Film, Media, and the Politics of Place, edited by Hamid Naficy, Routledge, 1999, pp. 17-41.

Tajes, María P. "Quiero contarte una historia: Migración e hibridez en Vientos de agua de Juan José Campanella." Hybridity in Spanish Culture, edited by María P. Tajes, Emily Knudson-Vilaseca and Maureen Tobin Stanley, Cambridge Scholars Publishing, 2011, pp. 121-145.

Trigo, Abril. "Migrancia: memoria: modernidá." Nuevas perspectivas desde/sobre América Latina. El desafio de los estudios culturales, edited by Mabel Moraña, Cuarto propio, 2000, pp. 273-292.

Wise, Amanda and Velayutham, Selvaraj. "Transnational Affect and Emotion in Migration Research." International Journal of Sociology, vol. 47, no. 2, 2017, pp. 116-130, Taylor \& Francis Online, doi: $10.1080 / 00207659.2017 .1300468$ 